\title{
Effects of Sex and Estrogen on Behavioral Sensitization to Cocaine in Rats
}

\author{
Ming Hu and Jill B. Becker \\ Psychology Department, Neuroscience Program and Reproductive Sciences Program, University of Michigan, Ann Arbor, Michigan 48109
}

Estrogen rapidly enhances dopamine (DA) activity in the striatum and nucleus accumbens as well as behavioral responses to psychomotor stimulants in female rats but not males. This experiment was conducted to investigate the role of pulsatile estrogen treatment on and sex differences in the development and expression of sensitization of cocaine-induced rotational behavior in rats with unilateral striatal DA denervation. Four groups were tested: ovariectomized (OVX) females treated with $5 \mu \mathrm{g}$ of estradiol benzoate $(0 \mathrm{VX}+\mathrm{E}), 0 \mathrm{VX}$ females, castrated (CAST) males, and intact males. Animals received estrogen or vehicle $30 \mathrm{~min}$ before cocaine (0, 5, 10, or 20 mg/kg, i.p.) on 4 consecutive days, followed by $3 \mathrm{~d}$ without treatment for 3 weeks. At the conclusion of the experiment, animals were withdrawn from hormone and/or cocaine for $10 \mathrm{~d}$, and all groups underwent a challenge test with $10 \mathrm{mg} / \mathrm{kg}$ cocaine. We report here that $\mathrm{OVX}+\mathrm{E}$ females exhibit significantly greater sensitization of rotational behavior with a faster rate of sensitization than the three other groups. There is also a sex difference independent of gonadal hormones: OVX females exhibit a greater magnitude of sensitization of rotational behavior than do CAST males at $20 \mathrm{mg} / \mathrm{kg}$ cocaine. Furthermore, on the challenge test, OVX $+\mathrm{E}$ animals tested without estrogen treatment continue to exhibit greater rotational behavior than do all other groups. Thus, estrogen enhances sensitization to cocaine, there are sex differences in behavioral sensitization, and sensitization that develops under conditions with estrogen persists even when estrogen levels are low.

Key words: cocaine; behavioral sensitization; rotational behavior; estrogen; sex differences; drug abuse

\section{Introduction}

Cocaine abuse by women has increased in the last decade, such that of the 1.8 million Americans who use cocaine, $\sim 30 \%$ are now female, making this a growing public health concern (Wetherington and Roman, 1995). Sex differences in the pattern of cocaine abuse and behavioral responses to cocaine indicate that the pattern of cocaine use and onset of addiction to cocaine is more rapid in women than in men (Lynch and Carroll, 1999). Women begin using cocaine and enter treatment at earlier ages than men (Griffin et al., 1989; Mendelson et al., 1991) and have more severe cocaine use at intake than men (Kosten et al., 1993). Furthermore, cocaine cues induce more drug craving in female than male addicts (Robbins et al., 1999). Collectively, these results suggest that women may be more sensitive to the addictive properties of cocaine than men.

Repeated exposure to psychomotor stimulants, such as cocaine, results in enhanced behavioral responses to subsequent drug treatment in humans and laboratory animals (Robinson and Becker, 1986; Strakowski et al., 1996). This effect of repeated drug treatments is known as behavioral sensitization. Sensitization-related neuroadaptations may play an important role in the processes of addiction and craving (Lett, 1989; Piazza et al., 1990; Robinson and Berridge, 1993; Berridge and Robinson, 1995; Wyvell and Berridge, 2001). In the laboratory, sex differences are found in behavioral sensitization induced by cocaine or amphetamine (AMPH), in which female rats have been

Received Aug. 21, 2002; revised 0ct. 8, 2002; accepted 0ct. 28, 2002.

This work was supported by United States Public Health Service Grant DA12677 from the National Institute for Drug Abuse. We thank Dr. Terry Robinson for fruitful discussions.

Correspondence should be addressed to Jill B. Becker, Psychology Department, Biopsychology Area, 525 East University, Ann Arbor, MI 48109-1109. E-mail: jbbecker@umich.edu.

Copyright $\odot 2003$ Society for Neuroscience $\quad 0270-6474 / 03 / 230693-07 \$ 15.00 / 0$ reported to exhibit greater sensitization than do intact male rats (Robinson et al., 1982; Glick and Hinds, 1984; Robinson, 1984; Camp and Robinson, 1988a,b; van Haaren and Meyer, 1991; Forgie and Stewart, 1994) and to sensitize at a lower dose of cocaine than male rats (Post et al., 1981).

Research on rodents suggests that ovarian hormones may play a role in sex differences in the response to acute treatment with psychomotor stimulants (Becker and Ramirez, 1981; Becker, 1990a, 1999, 2000). During naturally occurring behavioral estrus, AMPH- or cocaine-induced behaviors are greater than on other days of the estrous cycle (Becker et al., 1989; Sell et al., 2000). Ovariectomy attenuates, whereas estrogen treatment in ovariectomized female rats rapidly enhances, behaviors thought to be mediated by the striatal dopamine (DA) system (Becker, 1990a,b; Castner et al., 1993; Sell et al., 2000).

The role of ovarian hormones in development or expression of behavioral sensitization to psychomotor stimulants has been less well studied. In general, in rats, intact females or gonadal hormone-treated females exhibit greater sensitization of cocaineinduced locomotor activity or stereotyped behaviors than do ovariectomized females, although the results vary with dose of cocaine, dose of estrogen, and strain of rat (Peris et al., 1991; van Haaren and Meyer, 1991; Sircar and Kim, 1999; Sell et al., 2002). The present study was designed to further elucidate the role of the gonadal steroid hormone estrogen on and sex differences in cocaine-induced sensitization of rotational behavior.

\section{Materials and Methods}

Animals. Male and female Sprague Dawley rats (Harlan Sprague Dawley, Indianapolis, IN), weighing 200-225 gm at the start of the experiment, were housed two to three per cage under a 14/10 hr light/dark cycle. Animals were housed in a room maintained at a constant temperature of $20-21^{\circ} \mathrm{C}$, with phytoestrogen-free rodent chow (2014 Teklad Global 
14\% protein rodent maintenance diet, Harlan rat chow; Harlan Teklab, Madison, WI) and water available ad libitum. All procedures were performed according to a protocol approved by the University of Michigan Committee for Use and Care of Animals.

Surgery. Approximately 1 week after arrival, animals received 6-hydroxydopamine (6-OHDA) lesions of the nigrostriatal DA pathway according to the following protocol. Animals received $0.1 \mathrm{ml}$ of atropine methyl nitrate $(0.5 \mathrm{mg} / \mathrm{ml}$, i.p. $)$ to reduce salivation. Ten minutes later, animals were given pargyline $(35 \mathrm{mg} / \mathrm{kg}$, i.p.) to inhibit monoamine oxidase metabolism of 6-OHDA and desipramine $(15 \mathrm{mg} / \mathrm{kg}$, i.p) to protect noradrenergic cells and were anesthetized with sodium pentobarbital (for females, $20 \mathrm{mg} / \mathrm{kg}$, i.p.; for males, $25 \mathrm{mg} / \mathrm{kg}$, i.p.) supplemented with isoflurane. Lesion coordinates (based on a 200-250 gm rat) measured from bregma, skull flat, were as follows: posterior, $5.0 \mathrm{~mm}$; lateral, $2.0 \mathrm{~mm}$; and ventral, $7.7 \mathrm{~mm}$. A solution of $8.26 \mu \mathrm{g}$ of 6-OHDA hydrobromide ( $2 \mu \mathrm{g} / \mu \mathrm{l}$ in $0.1 \mathrm{mg} / \mathrm{ml} \mathrm{L}$-ascorbic acid in $0.9 \%$ sterile saline) was infused into the substantia nigra through a 29 gauge cannula at a rate of $0.5 \mu \mathrm{l} / \mathrm{min}$ for $8.25 \mathrm{~min}$ (for a total infusion of $\sim 4.13 \mu \mathrm{l}$ ). The infusion cannula was left in place for $2 \mathrm{~min}$ before being slowly raised to allow the infusion to disperse.

Two weeks later, all rats underwent gonadectomy or sham surgery under isoflurane anesthesia. For females, ovariectomy is conducted using a dorsal approach. The skin is opened with an incision $\sim 1 \mathrm{~cm}$ long along the midline just below the ribs, and a small incision $(\sim 0.5 \mathrm{~cm})$ is made through the muscle $\sim 1.5-2 \mathrm{~cm}$ lateral to the midline. The ovary is externalized with blunt forceps, and the tissue between the ovary and uterus is clamped with a hemostat. The ovary is removed, and the hemostat remains in place until there is no bleeding when it is released. The uterus with associated tissue is returned to the abdomen. The procedure is repeated on the other side, and wound closure is via $11 \mathrm{~mm}$ wound clips. During castration, the testes are removed via a ventral approach. For this procedure, the scrotal sac is opened, and the testis is visualized. The blood supply to the testis is closed with suture material, and the testis is removed. The wound is $\sim 0.5 \mathrm{~cm}$ and is closed with $11 \mathrm{~mm}$ wound clips. After $4 \mathrm{~d}$ of recovery, all female rats underwent vaginal lavage testing daily for 10 consecutive days to confirm cessation of cycling. Male rats were assigned randomly to receive either castration or sham castration surgery. On days in which female rats received vaginal lavage, male rats were handled.

Rotational behavior. Subjects were assigned to one of four groups: (1) ovariectomized (OVX) females treated with $5 \mu \mathrm{g}$ of estradiol benzoate in $0.1 \mathrm{ml}$ of peanut oil (EB) $(\mathrm{OVX}+\mathrm{E})$; (2) OVX females treated with $0.1 \mathrm{ml}$ of peanut oil vehicle; (3) castrated males treated with vehicle (CAST); and (4) sham-castrated males (SHAM) treated with vehicle. Each rat was injected subcutaneously with either EB or vehicle and then placed into the rotometer (Becker et al., 1982; McFarlane et al., 1992). After a 30 min habituation period, each rat was injected intraperitoneally with either saline or 5,10 , or $20 \mathrm{mg} / \mathrm{kg}$ cocaine and then tested for $1 \mathrm{hr}$. Numbers of animals in each group at each dose are included in the figure legends. The computer program recorded $360^{\circ}$ rotations in $5 \mathrm{~min}$ intervals for $60 \mathrm{~min}$ during the rotation test period. Rats were tested for 4 consecutive days and then had $3 \mathrm{~d}$ off each week for 3 consecutive weeks. On each test day, animals received $\mathrm{EB}$ or oil, and, on the $3 \mathrm{~d}$ off, no hormone or cocaine was administered.

This dose of EB and treatment regimen was chosen because it is known to produce concentrations of serum estrogen that are in the physiological range for the rat (Butcher et al., 1974; Henderson et al. 1977a,b). At this dose of EB per body weight, serum concentrations of estradiol peak within $1 \mathrm{hr}$ and return to baseline by $24 \mathrm{hr}$ (Cheng and Johnson, 1974). To demonstrate that this dose of EB is sufficient to induce a physiological response, prolactin and luteinizing hormone levels are lowered after daily treatment with $5 \mu \mathrm{g}$ of EB in the OVX rat but not with lower doses of EB even after $7 \mathrm{~d}$ of treatment (Mallampati and Johnson, 1973). We believe that this treatment regimen allows us to examine the acute response to estrogen treatment on each day of testing, but it is possible that there is some carryover. Thus, we chose to characterize this exposure to estrogen as "pulsatile" estradiol stimulation, because we know that, on each day, there will be a peak of estradiol during the time animals are tested behaviorally.
Challenge day. Ten days after the final testing day, all rats were tested in the rotometers as described above, with the exception that all rats were treated with $0.1 \mathrm{ml}$ of vehicle $30 \mathrm{~min}$ before the test, and all animals received $10 \mathrm{mg} / \mathrm{kg}$ cocaine as the challenge dose.

Striatal DA determination. After the challenge dose, all rats were decapitated; their brains were removed rapidly, and the striatum on each side was dissected. The two striatal samples were each weighed and then homogenized in $400 \mu \mathrm{l}$ of a solution containing an internal standard (dihydroxybenzylamine), $2 \mathrm{~mm}$ EDTA, and $0.1 \mathrm{~m}$ sodium metabisulfate dissolved in $0.05 \mathrm{~N}$ perchloric acid. These samples were then centrifuged at $5000 \times g$, filtered through $0.2 \mu \mathrm{m}$ filters, and transferred to autosampler vials for DA analysis using HPLC with electrochemical detection (Coulochem II; ESA, Waltham, MA), as described previously (Becker and Freed, 1988). Percentage DA depletions were calculated by subtracting the concentration of DA per milligram of wet tissue weight on the lesioned side from the value on the intact side. This result is divided by the value on the intact side, providing a percentage depletion of DA. Rats whose percentage depletion was $<95 \%$ and rats who turned in the wrong direction or who did not show a clear bias during testing were eliminated from the study.

Statistical analysis. The total number of net rotations was calculated as the sum of the number of contraversive rotations during the $60 \mathrm{~min}$ testing period minus the number of ipsiversive rotations for each rat. To determine the rate of sensitization, the data for all $12 \mathrm{~d}$ of testing were used for animals treated with $20 \mathrm{mg} / \mathrm{kg}$ cocaine, and the data for the first $8 \mathrm{~d}$ of testing were used for animals treated with 5 or $10 \mathrm{mg} / \mathrm{kg}$ cocaine. A linear regression was calculated for each animal using the days indicated above [when the increase in turning was most linear as determined by the correlation coefficient $\left(r^{2}\right)$ ]. The mean value of the slope for each group was calculated to predict the rate of sensitization.

All data were analyzed using the computer program Statview 4.5 (Systat, Evanston, IL) for Macintosh (Apple Computers, Cupertino, CA). Comparisons were made by ANOVA and subsequent post hoc comparisons with Fisher's PLSD test, with significance set at $p \leq 0.05$ for individual comparisons.

\section{Results}

All rats that were repeatedly treated with cocaine exhibited sensitization of rotational behavior, as defined by a progressive enhancement of behavior with repeated drug administration. On a two-way ANOVA test, there was a significant interaction between group and dose of cocaine $\left(F_{(9,1538)}=27.06, p<0.0001\right.$; group effect, $F_{(3,3)}=104.89, p<0.0001$; cocaine dose, $F_{(3,9)}=432.02$, $p<0.0001)$. When rotational data from session 12 were compared with rotational data from session 1 , with doses of 5,10 , and $20 \mathrm{mg} / \mathrm{kg}$ cocaine, all four groups showed a significant increase in behavior over the course of the experiment $(p<0.0001)$.

\section{Acute response to cocaine}

Acute effects of the first treatment with 5,10 , and $20 \mathrm{mg} / \mathrm{kg}$ cocaine or saline on rotational behavior are shown in Figure 1. Although there were slightly more rotations in the OVX $+\mathrm{E}$ and OVX female groups than in the CAST and SHAM male groups at the 5 and $10 \mathrm{mg} / \mathrm{kg}$ doses of cocaine, there was no significant effect of group $\left(F_{(3,3)}=0.937 ; p=0.4256\right)$ on the first day of testing. There was a significant effect of dose $\left(F_{(3,9)}=9.922 ; p<\right.$ 0.0001 ) on the first day of rotational behavior testing, so that all groups exhibited more rotational behavior with higher doses of cocaine than with lower doses (Fig. 1).

\section{Cocaine at $20 \mathrm{mg} / \mathrm{kg}$}

As shown in Figure 2, there were sex differences and effects of estrogen on sensitization of rotational behavior induced by repeated treatment with $20 \mathrm{mg} / \mathrm{kg}$ cocaine. First, all of the groups showed sensitization of rotational behavior, but the OVX $+\mathrm{E}$ group exhibited a greater rate of sensitization than did the other 


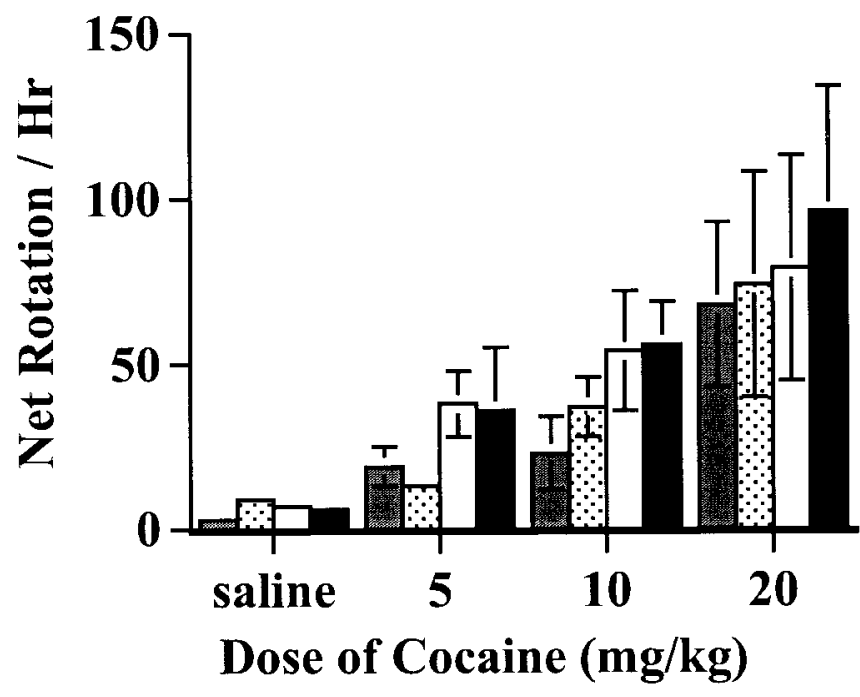

Figure 1. Net rotations per hour induced by saline or cocaine $(5,10$, or $20 \mathrm{mg} / \mathrm{kg})$ during the first test session. There were no group differences at any dose. Each bar represents the mean \pm SEM. Gray bars represent the data from SHAM (intact) male rats, stippled bars the data from CAST male rats, open bars the data from OVX female rats, and solid bars the data from $0 \mathrm{VX}+\mathrm{E}$ female rats.
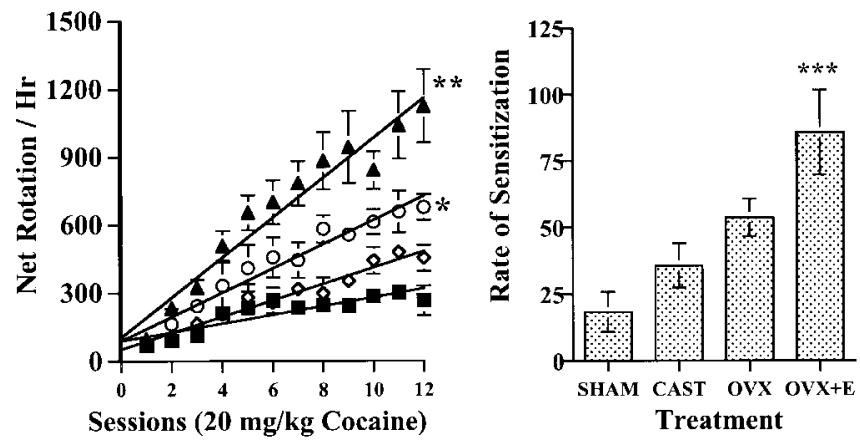

Figure 2. Effect of estrogen on and sex differences in rotational behavioral induced by repeated treatment with $20 \mathrm{mg} / \mathrm{kg}$ cocaine. Left, Mean \pm SEM number of net rotations per hour during each of the 12 test sessions. The $0 \mathrm{VX}+\mathrm{E}$ group ( $n=8$; solid triangles) was treated with $5 \mu \mathrm{g}$ of EB $30 \mathrm{~min}$ before $20 \mathrm{mg} / \mathrm{kg}$ cocaine. Open circles represent the data from OVX females $(n=8)$, open diamonds the data from CAST male rats $(n=8)$, and solid squares the data from SHAM male rats $(n=7)$. Right, Mean \pm SEM rate of sensitization from linear regression calculated for each rat from the data for the 12 testing sessions. *Net rotations per hour for OVX animals were significantly greater than SHAM $(p<0.0003)$ and CAST $(p<0.0001)$ groups; ** net rotations per hour for OVX + E animals were significantly greater than $\mathrm{OVX}(p<0.0001)$, CAST $(p<0.0001)$, and SHAM $(p<0.0001)$ groups; ${ }^{* * *}$ rates of sensitization for $0 \mathrm{VX}+\mathrm{E}$ animals were significantly greater than $0 \mathrm{VX}(p<0.038)$, CAST $(p<0.002)$, and SHAM $(p<$ 0.001) groups.

groups $\left(F_{(3,27)}=7.312 ; p<0.001\right)$. On post hoc comparisons, the rate of sensitization of the OVX $+\mathrm{E}$ group was greater than for the OVX group ( $p<0.0378)$, the CAST group $(p<0.0021)$, and the SHAM group $(p<0.001)$. There was no significant difference between OVX and CAST groups and no significant difference between the two male groups in the rate of sensitization.

When net rotations per hour were compared across testing days for animals receiving $20 \mathrm{mg} / \mathrm{kg}$ cocaine, there was a significant interaction between group and test session (group $\times$ session, $F_{(33,297)}=3.765, p<0.0001$; main effect of group, $F_{(3,27)}=$ $15.124, p<0.0001$; session, $\left.F_{(11,33)}=39.416, p<0.0001\right)$. In $p o s t$ hoc comparisons, the $\mathrm{OVX}+\mathrm{E}$ group exhibited more net rotations than did all other groups when the entire 12 sessions of behavior were compared $(p<0.0001)$. Furthermore, the OVX
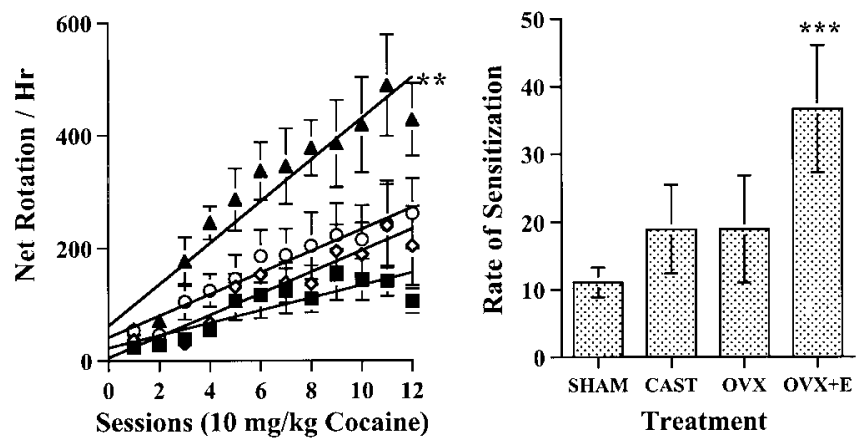

Figure 3. Effect of estrogen on and sex differences in rotational behavioral induced by repeated treatment with $10 \mathrm{mg} / \mathrm{kg}$ cocaine. Left, Mean \pm SEM number of net rotations per hour during each of the 12 test sessions. The $O V X+E$ group ( $n=9$; solid triangles) was treated with $5 \mu \mathrm{g}$ of EB $30 \mathrm{~min}$ before $10 \mathrm{mg} / \mathrm{kg}$ cocaine. Open circles represent the data from OVX females $(n=8)$, open diamonds the data from CAST male rats $(n=8)$, and solid squares the data from SHAM male rats $(n=7)$. Right, Mean \pm SEM rate of sensitization from linear regression calculated for each rat from the data for the first eight testing sessions. ${ }^{* *}$ Net rotations per hour for OVX+Eanimals were significantly greater than for OVX $(p<0.0001)$, CAST $(p<0.0001)$, and SHAM ( $p<0.0001)$ groups; ${ }^{* * *}$ rate of sensitization for OVX + E animals was significantly greater than for OVX $(p<0.038)$, CAST $(p<0.022)$, and SHAM $(p<0.014)$ groups.

group receiving $20 \mathrm{mg} / \mathrm{kg}$ cocaine exhibited more net rotations than did either male group ( $p<0.003$ ). There was no significant difference between the CAST and SHAM groups.

\section{Cocaine at $10 \mathrm{mg} / \mathrm{kg}$}

With $10 \mathrm{mg} / \mathrm{kg}$ cocaine, all of the groups again showed sensitization of rotational behavior (Fig. 3), but the OVX+E group exhibited a greater rate of sensitization and more net rotations than did all other groups. On a one-way ANOVA test of the slopes of all groups, there was a main effect of group $\left(F_{(3,28)}=0.043 ; p<\right.$ $0.001)$, indicating group differences in the rate of sensitization. Post hoc comparisons indicated that the OVX +E group sensitized more rapidly than did the OVX group ( $p<0.0383)$, the CAST group $(p<0.0215)$, and the SHAM group $(p<0.0141)$. There was no significant difference between the OVX and CAST groups and no significant difference between the two male groups.

On a two-way ANOVA test, there was a significant interaction between group and session in the number of net rotations $\left(F_{(3,11)}=1.572, p<0.028\right.$; group $F_{(3,27)}=11.684, p<0.0001$; session, $\left.F_{(11,33)}=18.486, p<0.0001\right)$. In post hoc comparisons, the OVX $+\mathrm{E}$ group receiving $10 \mathrm{mg} / \mathrm{kg}$ cocaine exhibited more net rotations than did all other groups when the entire 12 sessions of behavior were compared ( $p<0.0001)$. There was no significant difference between the OVX, CAST, and SHAM groups.

\section{Cocaine at $5 \mathrm{mg} / \mathrm{kg}$}

As illustrated in Figure 4, estrogen also enhanced the rate of sensitization and net rotations induced by repeated treatment with 5 $\mathrm{mg} / \mathrm{kg}$ cocaine. All of the groups showed an increase in rotational behavior over the 12 testing sessions, but the OVX $+\mathrm{E}$ female groups exhibited greater net rotations during the 12 testing sessions than did all other groups. On a one-way ANOVA test, there were group differences in the rate of sensitization in rotations $\left(F_{(3,34)}=3.871 ; p<0.0175\right)$. On post hoc comparisons, the rate of sensitization of the OVX + E group was greater than that of the CAST $(p<0.0041)$ and SHAM $(p<0.0109)$ groups. There was no significant difference between the OVX $+\mathrm{E}$ and OVX groups, between the OVX and CAST groups, and between the two male groups.

On a two-way ANOVA, there was a significant interaction 

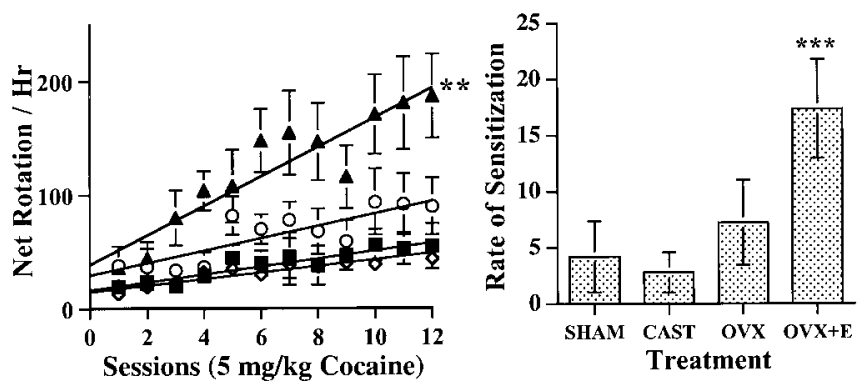

Figure 4. Effect of estrogen on and sex differences in rotational behavior induced by repeated treatment with $5 \mathrm{mg} / \mathrm{kg}$ cocaine. Left, Mean \pm SEM number of net rotations per hour during each of the 12 test sessions. The $\mathrm{VXX}+\mathrm{E}$ group ( $n=11$; solid triangles) was treated with $5 \mu \mathrm{g}$ of EB $30 \mathrm{~min}$ before $5 \mathrm{mg} / \mathrm{kg}$ cocaine. Open circles represent the data from OVX females $(n=8)$, open diamonds the data from CAST male rats $(n=10)$, and solid squares the data from SHAM male rats $(n=9)$. Right, Mean \pm SEM rate of sensitization from linear regression calculated for each rat from the data for the first eight testing sessions. **Net rotations per hour for OVX+Eanimals were significantly greater than for $\mathrm{OVX}(p<0.0001)$, CAST $(p<0.0001)$, and SHAM ( $p<0.0001$ ) groups; ${ }^{* * *}$ rate of sensitization for $0 \mathrm{VX}+\mathrm{E}$ animals was significantly greater than for CAST $(p<0.004)$ and SHAM $(p<0.01)$ groups.
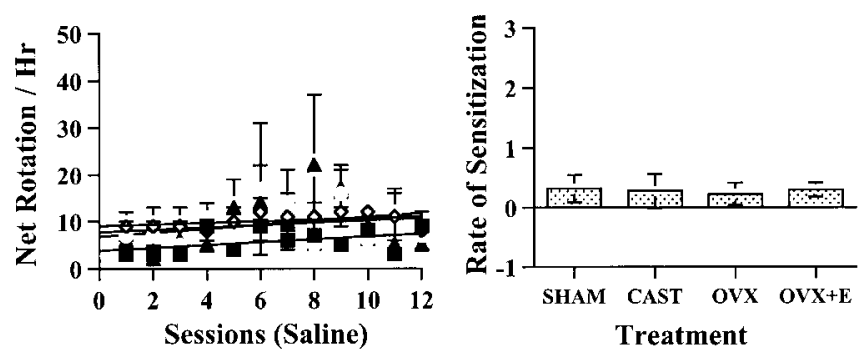

Figure 5. No effect of estrogen or sex on rotational behavioral induced by saline. Left, Mean \pm SEM number of net rotations per hour on each of the 12 test sessions. The $0 V X+E$ group ( $n=7$; solid triangles) were treated with $5 \mu \mathrm{g}$ of EB 30 min before saline. Open circles represent the data from OVX females $(n=8)$, open diamonds the data from CAST male rats $(n=7)$, and solid squares the data from SHAM male rats $(n=7)$. Right, Mean \pm SEM rate of change in rotations calculated from linear regressions calculated for each rat from the data for 12 testing sessions.

between group and session $\left(F_{(33,308)}=2.088, p<0.0007\right.$; effect of group, $F_{(3,28)}=8.953, p<0.0003$; effect of session, $F_{(11,28)}=$ $10.635, p<0.0001)$. In post hoc comparisons, the OVX + E group receiving $5 \mathrm{mg} / \mathrm{kg}$ cocaine exhibited greater rotational behavior than did all other groups when the entire 12 sessions of behavior were compared ( $p<0.0001)$. There were no significant differences between the OVX, CAST, and SHAM groups.

\section{Saline}

There was no effect of repeated saline treatment on rotational behavior (Fig. 5). None of the groups showed increased rotational behavior over the 12 testing sessions. A one-way ANOVA test of the slopes of all groups indicated that there was no effect of group $\left(F_{(3,25)}=0.038 ; p=0.99\right)$. When net rotations were compared on a two-way ANOVA, there was no significant interaction between groups and sessions $\left(F_{(33,275)}=0.869 ; p=0.677\right)$.

\section{Dose-response}

All groups exhibited differences in the magnitude or rate of sensitization depending on dose of cocaine (compare Figs. 2-5). For the OVX $+\mathrm{E}$ group, there was a significant effect of dose on the rate of sensitization $\left(F_{(3,31)}=15.886 ; p<0.0001\right)$. On post hoc comparisons, the rate of sensitization of the OVX $+\mathrm{E}$ rats treated with $20 \mathrm{mg} / \mathrm{kg}$ cocaine was greater $(p<0.001)$ than for the 10 $\mathrm{mg} / \mathrm{kg}$ group, the $5 \mathrm{mg} / \mathrm{kg}$ group, and the saline group. The rate of sensitization of the OVX $+\mathrm{E}$ rats treated with $10 \mathrm{mg} / \mathrm{kg}$ cocaine was greater than that of the saline group $(p<0.015)$ but not the $5 \mathrm{mg} / \mathrm{kg}$ group. There was also a significant effect of dose on the magnitude of sensitization $\left(F_{(3,594)}=281.23 ; p<0.0001\right)$. On post hoc comparisons, all dose groups were significantly different from each other $(p<0.0001)$.

There was a significant effect of dose on the rate of sensitization for the OVX group $\left(F_{(3,28)}=18.427 ; p<0.0001\right)$. On post hoc comparisons, the rate of sensitization of the OVX rats treated with $20 \mathrm{mg} / \mathrm{kg}$ cocaine was greater $(p<0.001)$ than the other doses of cocaine. The rate of sensitization of the OVX rats treated with $10 \mathrm{mg} / \mathrm{kg}$ cocaine was greater than that of the saline group $(p<0.025)$ but not the $5 \mathrm{mg} / \mathrm{kg}$ group. There was also a significant effect of dose on the magnitude of sensitization $\left(F_{(3,380)}=\right.$ $132.847 ; p<0.0001)$. On post hoc comparisons, for the $5 \mathrm{mg} / \mathrm{kg}$ versus the saline group, the confidence level was $p=0.0174$; for the rest of the comparisons across doses, the confidence level was at $p<0.0001$.

For the CAST group, there was a significant effect of dose on the rate of sensitization $\left(F_{(3,29)}=9.649 ; p<0.0001\right)$. On post hoc comparisons, the rate of sensitization of the CAST rats treated with $20 \mathrm{mg} / \mathrm{kg}$ cocaine was greater than that of the $10 \mathrm{mg} / \mathrm{kg}$ group ( $p<0.0345)$, the $5 \mathrm{mg} / \mathrm{kg}$ group $(p<0.0001)$, and the saline group $(p<0.0001)$. The rate of sensitization of the CAST rats treated with $10 \mathrm{mg} / \mathrm{kg}$ cocaine was greater than that of the 5 $\mathrm{mg} / \mathrm{kg}$ group $(p<0.0295)$ and saline group $(p<0.0232)$. There was also a significant effect of dose on the magnitude of sensitization $\left(F_{(3,390)}=121.791 ; p<0.0001\right)$. On post hoc comparisons, the responses at all doses were significantly different $(p<$ 0.0001 ), except for the $5 \mathrm{mg} / \mathrm{kg}$ versus saline groups, which did not differ $(p=0.1379)$.

For the SHAM group, there was a significant effect of dose on the rate of sensitization $\left(F_{(3,26)}=4.351 ; p<0.013\right)$. On post hoc comparisons, the rate of sensitization of the SHAM rats treated with $20 \mathrm{mg} / \mathrm{kg}$ cocaine was greater than that of the $5 \mathrm{mg} / \mathrm{kg}$ group $(p<0.0089)$ and saline group $(p<0.0033)$ but not the $10 \mathrm{mg} / \mathrm{kg}$ group. There was also a significant effect of dose on the magnitude of sensitization $\left(F_{(3,354)}=112.58 ; p<0.0001\right)$. On post hoc comparisons, the power of the significance level for $5 \mathrm{mg} / \mathrm{kg}$ versus saline was $p=0.0038$; for the rest of the comparisons across doses, the confidence level was at $p<0.0001$.

\section{Challenge day}

On the challenge day ( $10 \mathrm{~d}$ after the last day of the original test schedule), all rats received $10 \mathrm{mg} / \mathrm{kg}$ cocaine, but no groups were treated with estrogen. The OVX + E groups showed significantly more net rotations than the other three groups, regardless of previous cocaine history (Fig. 6). When net rotations were compared, there was a significant effect of group $\left(F_{(3,9)}=13.771 ; p<\right.$ $0.0001)$ and no interaction between previous dose and group $\left(F_{(3,59)}=1.815 ; p=0.154\right)$. There was no significant difference between groups with previous saline treatment $\left(F_{(3,25)}=2.088\right.$; $p=0.127)$. When the response on the challenge day for each cocaine-treated group was compared with the response of the comparable saline-treated groups, all groups showed sensitization after pretreatment with 10 or $20 \mathrm{mg} / \mathrm{kg}$, but after pretreatment with $5 \mathrm{mg} / \mathrm{kg}$, the mean responses to the $10 \mathrm{mg} / \mathrm{kg}$ challenge dose were not different from the responses of the salinepretreated animals, except for the OVX + E group $(p=0.023)$ (Fig. 6). 


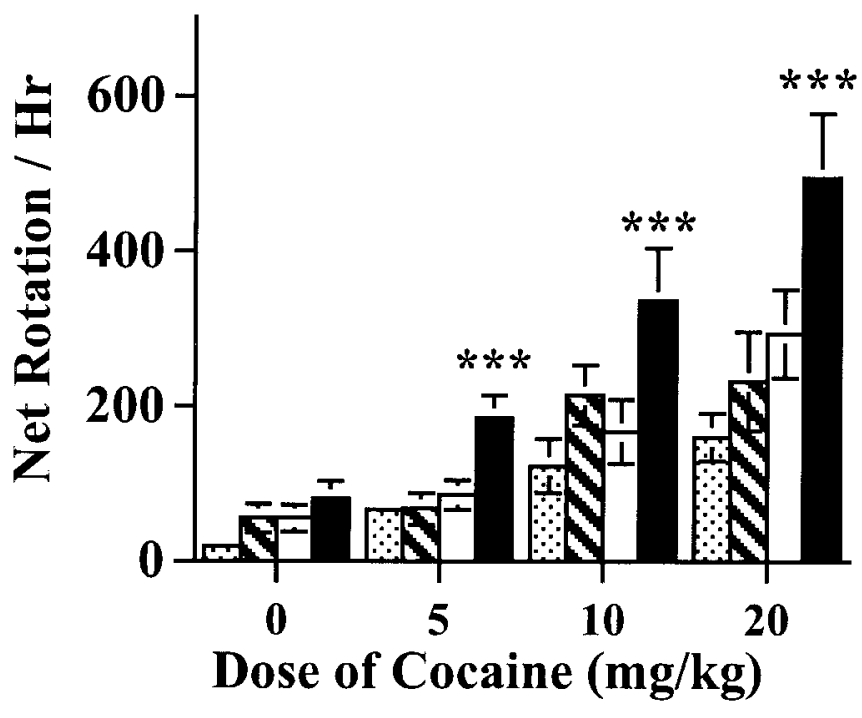

Figure 6. Challenge day: mean \pm SEM number of net rotations per hour. On the challenge day ( $10 \mathrm{~d}$ after the last day of the original test schedule), all rats received $10 \mathrm{mg} / \mathrm{kg}$ cocaine, but no groups were treated with estrogen. Gray bars represent the data from SHAM male rats, stippled bars the data from CAST male rats, open bars the data from OVX female rats, and solid bars the data from $\mathrm{OVX}+\mathrm{E}$ female rats. ${ }^{* *}$ Net rotations per hour for $\mathrm{OVX}+\mathrm{E}$ animals were significantly greater than for $\mathrm{OVX}(p<0.0013)$, CAST $(p<0.0004)$, and SHAM groups $(p<$ 0.0001).

\section{Discussion}

This is the first study to demonstrate sex differences in behavioral sensitization in the absence of gonadal hormones and that pulsatile estrogen treatment enhances sensitization of cocaineinduced rotational behavior in OVX female rats. At $20 \mathrm{mg} / \mathrm{kg}$, OVX females exhibit a greater magnitude of sensitization than do CAST males. At all doses of cocaine tested, OVX $+\mathrm{E}$ rats exhibited greater magnitude of sensitization of rotational behavior to cocaine and a significantly greater rate of sensitization than did OVX rats and both male groups, demonstrating that estrogen enhances the rate and magnitude of sensitization of cocaineinduced rotational behavior.

In this study, we did not find sex differences or effects of estrogen on the first acute response to cocaine. This finding is consistent with reports of no sex differences in cocainestimulated motor behavior in rats (Craft and Stratman, 1996; Cailhol and Mormede, 1999) and in mice (Sershen et al., 1998). However, others have reported that intact females exhibit greater stereotyped behaviors and locomotor activity induced by acute cocaine than do males (van Haaren and Meyer, 1991; Sell et al., 2000; Walker et al., 2001). The differences in the results of these studies could be a result of the difference between the acute estrogen exposure on the first day of the study reported here versus more extensive estrogen treatment (i.e., silastic capsules filled with estradiol) or intact females (that have been exposed to estrogen for a few days). It is also possible that, on the first day of testing, the behavioral response is influenced by the animal's previous experience. For example, Walker et al. (2001) reported no difference between intact and OVX in the acute response to 10 $\mathrm{mg} / \mathrm{kg}$ cocaine if animals underwent vaginal lavage, whereas OVX females that were not handled in this way exhibited less activity. All of our animals were handled extensively before the beginning of the experiment and underwent vaginal lavage for $10 \mathrm{~d}$.

Extensive literature documents that females have a greater acute response to AMPH than males (Meyer, 1977; Savageau and
Beatty, 1981; Becker et al., 1982, 1999; Camp et al., 1986; Camp and Robinson, 1988a; Becker and Cha, 1989). There is also estrous cycle-dependent variation in behavior induced by AMPH (Becker et al., 1982; Becker and Cha, 1989), and estrogen rapidly enhances the behavioral and neurochemical response to AMPH (Becker, 1990; Becker and Rudick, 1999). Differences in the actions of AMPH versus cocaine may underlie the different results found here for cocaine and the response to AMPH in other studies. AMPH and cocaine both act at the DA transporter to prevent DA reuptake, but $\mathrm{AMPH}$ has an added effect of inducing the release of DA (Pifl and Singer, 1999; Sitte et al., 2001). This additional effect of AMPH may exacerbate the acute response to the drug and produce behavioral effects not seen with cocaine.

Although ovariectomy reduces the acute response to AMPH, both intact and OVX female rats show AMPH-induced sensitization (Camp and Robinson, 1988b). Because the two groups do not exhibit the same magnitude of initial behavior response, it has been difficult to evaluate whether there was an effect of ovarian hormones on sensitization to AMPH. One must decide what is the best measure of sensitization: the absolute change, the rate of change, or the percentage change in behavior. When groups start out with a different initial response, one can get very different answers, depending on the metric that is used to assess sensitization. The failure to find an initial difference between groups in the response to cocaine in the study presented here makes it possible to directly compare both the magnitude and rate of cocaine-induced behavioral sensitization across groups, and we find that sex of the animal and estrogen treatment affect both.

Camp and Robinson (1988a) reported that female rats exhibit greater AMPH-induced sensitization than do male rats, even when given a lower dose of AMPH. Other studies have reported sex differences in sensitization of AMPH-induced rotational behavior at a high dose of AMPH but not at a low dose (Robinson, 1984). With cocaine, females again are reported to exhibit greater behavioral sensitization than males (van Haaren and Meyer, 1991). Female rats also demonstrate a higher level of sensitization to repeated cocaine administration (Glick and Hinds, 1984) and become sensitized with a lower dose of cocaine than male rats (Post et al., 1981). These studies, however, did not address whether the sex differences are a result of sex differences in circulating gonadal hormones (i.e., activational effects) or developmental sex differences (i.e., organizational effects), as we do in the study reported here.

A few studies have addressed effects of estrogen on cocaineinduced behavioral sensitization. Peris et al. (1991) showed that OVX female rats treated with chronic estrogen display a significantly greater degree of cocaine-induced behavioral sensitization. Chronic estrogen also increased sensitivity of female rats to repeated cocaine treatment (Sircar and Kim, 1999). Recently, Sell et al. (2002) reported that, in OVX rats with chronic estrogen implants, there is an enhanced response to repeated cocaine treatments, although in this study, estrogen alone increased the first response to cocaine, so it is not clear that there was enhanced sensitization (Sell et al., 2002). Extremely high doses of estradiol or chronic treatment with physiological doses of estrogen have been shown to induce downregulation of presynaptic DA activity (Di Paolo et al., 1982, 1983; Morissette and Di Paolo, 1993) and produce DA receptor supersensitivity (Hruska and Silbergeld, 1980; Di Paolo et al., 1981, 1994; Hruska, 1986; Morissette et al., 1992). During the estrous cycle, the female rat is exposed to an increase in estradiol that occurs primarily during the morning of proestrus and falls rapidly after that (McCarthy and Becker, 2002). We argue, therefore, that the effect of chronic estrogen on 
cocaine-induced sensitization seen in previous studies may not be mediated by the same mechanisms that make intact female rats more responsive to cocaine sensitization than male rats and that the pulsatile estrogen treatment schedule used here is more appropriate for assessing physiological mechanisms.

Intriguingly, for male rats, CAST decreases AMPH-induced sensitization without affecting the acute behavioral response to AMPH (Robinson, 1984; Forgie and Stewart, 1994). Attempts to enhance sensitization in CAST males by replacing testosterone, however, have not been successful (Forgie and Stewart, 1994), so the mechanism mediating the effect of CAST on sensitization to AMPH remains to be determined. In this study, we did not find a difference between SHAM and CAST rats in sensitization to cocaine at any dose.

Intact male rats metabolize AMPH more rapidly than females, so less AMPH reaches the brain (Becker et al., 1982). However, even when male and female rats are given different doses of AMPH to produce equivalent brain concentrations of the drug, females still exhibit a greater behavioral response (Becker et al., 1982; Camp et al., 1986). Thus, differences in drug metabolism cannot entirely explain the sex difference in response to AMPH. In contrast to AMPH, plasma and brain concentrations of cocaine are the same in male and female rats after intraperitoneal injection (Bowman et al., 1999). Furthermore, the same study showed that ovariectomy and castration did not affect plasma and brain cocaine concentrations. Thus, the sex differences in response to AMPH and cocaine may result from innate differences in their neural targets, most likely the dopamine system.

Finally, the results of this study on the challenge day present exciting new information about the persistence of the effect of estrogen on sensitization. The use of a challenge dose after a 7-10 $\mathrm{d}$ withdrawal period is a common way to determine the persistence of the effect of the sensitization to the drug. Although we assume that estradiol was no longer elevated at this time, we did not measure serum values in these animals. Thus, the reader must be aware that it is possible that we did not fully achieve zero estrogen on the challenge day. Nevertheless, the enhancement of behavior seen in OVX+E animals over OVX animals in the absence of additional estrogen treatment is a phenomenon not tested or seen in previous studies. The significance of the differences between the OVX $+\mathrm{E}$ and the OVX female rats on the challenge day, in the absence of estrogen treatment, suggests that there are long-term effects of cocaine exposure in the presence of estrogen that differ from the effects of cocaine exposure alone. The repercussions of the application of this model to human drug addiction are intriguing; it indicates that sensitization accrued during drug use under conditions of enhanced estrogen will persist even when estrogen levels are low.

It has been reported that women are less likely to try cocaine, but the likelihood that someone who has tried cocaine will develop lifelong cocaine dependence is greater for women than for men (Kandel et al., 1995; Wetherington and Roman, 1995). In addition, a recent report by Justice and de Wit (1999) reports that higher levels of estrogen are associated with greater amphetamine-induced euphoria, energy, and intellectual efficiency. We interpret these results as indicating that there are differences between men and women in the neurobiological consequences of being exposed to the psychomotor stimulants that result in women being at increased risk for addiction to these drugs. Sensitization has been proposed as one of the possible behavioral correlates of craving, and, because females exhibit greater sensitization to cocaine than do males, we believe that this is a viable animal model with which to begin to examine sex differences in the neurobiological consequences of repeated cocaine administration.
The results of our study may lead to a better understanding of the underlying neurobiological mechanisms mediating this sex difference. The ultimate goal would be to target treatments to reduce this risk. At the very least, understanding the cause of the greater risk of addiction for women may contribute to better intervention and prevention strategies.

\section{References}

Becker JB (1990a) Direct effect of 17 $\beta$-estradiol on striatum: sex differences in dopamine release. Synapse 5:157-164.

Becker JB (1990b) Estrogen rapidly potentiates amphetamine-induced striatal dopamine release and rotational behavior during microdialysis. Neurosci Lett 118:169-171.

Becker JB (1999) Gender differences in and influences of reproductive hormones on dopaminergic function in striatum and nucleus accumbens. Pharmacol Biochem Behav 64:803-812.

Becker JB (2000) Oestrogen effects on dopaminergic function in striatum. In: Neuronal and cognitive effects of oestrogens (Chadwick DJ, Goode JA, eds), pp 134-151. Chichester, UK: Wiley.

Becker JB, Cha J (1989) Estrous cycle-dependent variation in amphetamine-induced behaviors and striatal dopamine release assessed with microdialysis. Behav Brain Res 35:117-125.

Becker JB, Freed WJ (1988) Neurochemical correlates of behavioral changes following intraventricular adrenal medulla grafts: intraventricular microdialysis in freely moving rats. Prog Brain Res 78:527-533.

Becker JB, Ramirez VD (1981) Sex differences in the amphetamine stimulated release of catecholamines from rat striatal tissue in vitro. Brain Res 204:361-372.

Becker JB, Rudick CN (1999) Rapid effects of estrogen or progesterone on the amphetamine-induced increase in striatal dopamine are enhanced by estrogen priming: a microdialysis study. Pharmacol Biochem Behav 64:53-57.

Becker JB, Robinson TE, Lorenz KA (1982) Sex differences and estrous cycle variations in amphetamine-elicited rotational behavior. Eur J Pharmacol 80:65-72.

Berridge KC, Robinson TE (1995) The mind of an addicted brain: neural sensitization of wanting versus liking. Curr Direct Psychol Sci 4:71-76.

Bowman BP, Vaughan SR, Walker QD, Davis SL, Little PJ, Scheffler NM, Thomas BF, Kuhn CM (1999) Effects of sex and gonadectomy on cocaine metabolism in the rat. J Pharmacol Exp Ther 290:1316-1323.

Butcher RL, Collins WE, Fugo NW (1974) Plasma concentration of LH, FSH, prolactin, progesterone and estradiol-17beta throughout the 4-day estrous cycle of the rat. Endocrinology 94:1704-1708.

Cailhol S, Mormede P (1999) Strain and sex differences in the locomotor response and behavioral sensitization to cocaine in hyperactive rats. Brain Res 842:200-205.

Camp DM, Robinson TE (1988a) Susceptibility to sensitization. I. Sex differences in the enduring effects of chronic D-amphetamine treatment on locomotion, stereotyped behavior and brain monoamines. Behav Brain Res 30:55-68.

Camp DM, Robinson TE (1988b) Susceptibility to sensitization. II. The influence of gonadal hormones on enduring changes in brain monoamines and behavior produced by the repeated administration of D-amphetamine or restraint stress. Behav Brain Res 30:69-88.

Camp DM, Becker JB, Robinson TE (1986) Sex differences in the effects of gonadectomy on amphetamine-induced rotational behavior in rats. Behav Neural Biol 46:491-495.

Castner SA, Xiao L, Becker JB (1993) Sex differences in striatal dopamine: in vivo microdialysis and behavioral studies. Brain Res 610:127-134.

Cheng HC, Johnson DC (1974) Temporal changes in serum estradiol and prolactin in immature female rats given a single injection of estradiol benzoate. Steroids 24:657-664.

Craft RM, Stratman JA (1996) Discriminative stimulus effects of cocaine in female versus male rats. Drug Alcohol Depend 42:27-37.

Di Paolo T (1994) Modulation of brain dopamine transmission by sex steroids. Rev Neurosci 5:27-41.

Di Paolo T, Poyet P, Labrie F (1981) Effect of chronic estradiol and haloperidol treatment on striatal dopamine receptors. Eur J Pharmacol 73:105-106.

Di Paolo T, Dupont A, Daigle M (1982) Effect of chronic estradiol treatment on dopamine concentrations in discrete brain nuclei of hypophysectomized female rats. Neurosci Lett 32:295-300. 
Di Paolo T, Diagle M, Picard V, Barden N (1983) Effect of acute and chronic 17 beta-estradiol treatment on serotonin and 5-hydroxyindole acetic acid content of discrete brain nuclei of ovariectomized rat. Exp Brain Res 51:73-76.

Forgie ML, Stewart J (1994) Sex difference in amphetamine-induced locomotor activity in adult rats: role of testosterone exposure in the neonatal period. Pharmacol Biochem Behav 46:637-645.

Glick SD, Hinds PA (1984) Sex differences in sensitization to cocaineinduced rotation. Eur J Pharmacol 99:119-121.

Griffin ML, Weiss RD, Lange U (1989) A comparison of male and female cocaine abuse. Arch Gen Psychiatry 46:122-126.

Henderson SR, Baker C, Fink G (1977a) Oestradiol-17 $\beta$ and pituitary responsiveness to luteinizing hormone releasing factor in the rat: a study using rectangular pulses of estradiol-17 $\beta$ monitored by nonchromatographic radioimmunoassay. J Endocrinol 73:441-453.

Henderson SR, Baker C, Fink G (1977b) Effect of oestradiol-17beta exposure on the spontaneous secretion of gonadotrophins in chronically gonadectomized rats. J Endocrinol 73:455-462.

Hruska RE (1986) Elevation of striatal dopamine receptors by estrogen: dose and time studies. J Neurochem 47:1908-1915.

Hruska RE, Silbergeld EK (1980) Estrogen treatment enhances dopamine receptor sensitivity in the rat striatum. Eur J Pharmacol 61:397-400.

Justice AJH, de Wit H (1999) Acute effects of D-amphetamine during the follicular and luteal phases of the menstrual cycle in women. Psychopharmacology (Berl) 145:67-75.

Kandel DB, Warner MPP, Kessler RC (1995) The epidemiology of substance abuse and dependence among women. In: Drug addiction research and the health of women. Rockville, MD: United States Department of Health and Human Resources.

Kosten TA, Gawin FH, Kosten TR, Rounsaville BJ (1993) Gender differences in cocaine use and treatment response. J Subst Abuse Treat 10:63-66.

Lett BT (1989) Repeated exposures intensify rather than diminish the rewarding effects of amphetamine, morphine, and cocaine. Psychopharmacology (Berl) 98:357-362.

Lynch WJ, Carroll ME (1999) Sex differences in the acquisition of intravenously self-administered cocaine and heroin in rats. Psychopharmacology (Berl) 144:77-82.

Mallampati RS, Johnson DC (1973) Serum and pituitary luteinizing hormone, follicle stimulating hormone, and prolactin in gonadectomized male, female and androgenized female rats treated with oestradiol benzoate. J Endocrinol 59:209-216.

McCarthy MM, Becker JB (2002) Neuroendocrinology of sexual behavior in the female. In: Behavioral endocrinology (Becker JB, Breedlove SM, Crews D, McCarthy MM, eds), pp 117-151. Cambridge, MA: MIT/Bradford.

McFarlane DK, Martonyi BJ, Robinson TE (1992) An inexpensive automated system for the measurement of rotational behavior in small animals. Behav Res Methods Instrum Comput 24:414-419.

Mendelson JH, Weiss R, Griffin M, Mirin SM, Teoh SK, Mello NK, Lex BW (1991) Some special considerations for treatment of drug abuse and dependence in women. NIDA Res Monogr 106:313-327.

Meyer Jr E (1977) Age-and sex-related differences in amphetamineinduced locomotor activity. Fed Proc 36:1033.

Morissette M, Di Paolo T (1993) Effect of chronic estradiol and progesterone treatments of ovariectomized rats on brain dopamine uptake sites. J Neurochem 60:1876-1883.

Morissette M, Levesque D, Di Paolo T (1992) Effect of chronic estradiol treatment on brain dopamine receptor reappearance after irreversible blockade: an autoradiographic study. Mol Pharmacol 42:480-488.

Peris J, Decambre N, Coleman-Hardee M, Simpkins J (1991) Estradiol enhances behavioral sensitization to cocaine and amphetamine-stimulated $\left[{ }^{3} \mathrm{H}\right]$ dopamine release. Brain Res 566:255-264.
Piazza PV, Deminière JM, Le Moal M, Simon H (1990) Stress- and pharmacologically-induced behavioral sensitization increases vulnerability to acquisition of amphetamine self-administration. Brain Res 514:22-26.

Pifl C, Singer EA (1999) Ion dependence of carrier-mediated release in dopamine or norepinephrine transporter-transfected cells questions the hypothesis of facilitated exchange diffusion. Mol Pharmacol 56:1047-1054.

Post RM, Lockfeld A, Squillace KM, Contel NR (1981) Drug-environment interaction: context dependency of cocaine-induced behavioral sensitization. Life Sci 28:755-760.

Robbins SJ, Ehrman RN, Childress AR, O’Brien CP (1999) Comparing levels of cocaine cue reactivity in male and female outpatients. Drug Alcohol Depend 53:223-230.

Robinson TE (1984) Behavioral sensitization: characterization of enduring changes in rotational behavior produced by intermittent injections of amphetamine in male and female rats. Psychopharmacology (Berl) $84: 466-475$.

Robinson TE, Becker JB (1986) Enduring changes in brain and behavior produced by chronic amphetamine administration: a review and evaluation of animal models of amphetamine psychosis. Brain Res Rev 396:157-198.

Robinson TE, Berridge KC (1993) The neural basis of drug craving: an incentrive-sensitization theory of addiction. Brain Res Rev 18:247-291.

Robinson TE, Becker JB, Presty SK (1982) Long-term facilitation of amphetamine-induced rotational behavior and striatal dopamine release produced by a single exposure to amphetamine: sex differences. Brain Res 253:231-241.

Savageau MM, Beatty WW (1981) Gonadectomy and sex differences in the behavioral responses of amphetamine and apomorphine of rats. Pharmacol Biochem Behav 14:17-23.

Sell SL, Scalzitti JM, Thomas ML, Cunningham KA (2000) Influence of ovarian hormones and estrous cycle on the behavioral response to cocaine in female rats. J Pharmacol Exp Ther 293:879-886.

Sell SL, Thomas ML, Cunningham KA (2002) Influence of estrous cycle and estradiol on behavioral sensitization to cocaine in female rats. Drug Alcohol Depend 67:281-290.

Sershen H, Hashim A, Lajtha A (1998) Gender differences in kappa-opioid modulation of cocaine-induced behavior and NMDA-evoked dopamine release. Brain Res 801:67-71.

Sircar R, Kim D (1999) Female gonadal hormones differentially modulate cocaine-induced behavioral sensitization in Fischer, Lewis, and SpragueDawley rats. J Pharmacol Exp Ther 289:54-65.

Sitte HH, Hiptmair B, Zwach J, Pifl C, Singer EA, Scholze P (2001) Quantitative analysis of inward and outward transport rates in cells stably expressing the cloned human serotonin transporter: inconsistencies with the hypothesis of facilitated exchange diffusion. Mol Pharmacol 59:1129-1137.

Strakowski SM, Sax KW, Setters MJ, Keck Jr PE (1996) Enhanced response to repeated D-amphetamine challenge: evidence for behavioral sensitization in humans. Biol Psychiatry 40:872-880.

van Haaren F, Meyer M (1991) Sex differences in the locomotor activity after acute and chronic cocaine administration. Pharmacol Biochem Behav 39:923-927.

Walker QD, Cabassa J, Kaplan KA, Li ST, Haroon J, Spohr HA, Kuhn CM (2001) Sex differences in cocaine-stimulated motor behavior: disparate effects of gonadectomy. Neuropsychopharmacology 25:118-130.

Wetherington CL, Roman AR (1995) Drug addiction research and the health of women, pp 105-130. Rockville, MD: United States Department of Health and Human Services.

Wyvell CL, Berridge KC (2001) Incentrive sensitization by previous amphetamine exposure: increased cue-triggered "wanting" for sucrose reward. J Neurosci 21:7831-7840. 